\title{
Titanium Dioxide Nanoparticle Coating in Fluidized Bed via Supercritical Anti-solvent process (SAS)
}

Víctor Martín ${ }^{1}$, Rut Romero-Díez ${ }^{1}$, Soraya Rodríguez-Rojo*, María José Cocero

High Pressure Processes Group, Department of Chemical Engineering and Environmental Technology, School of Engineering. Venue Dr. Mergelina, University of Valladolid.

Dr. Mergelina s/n, 47011, Valladolid, Spain

*Corresponding author:

E-mail address: sorayarr@iq.uva.es (S. Rodríguez-Rojo)

${ }^{1}$ These authors have contributed equally to the development of this work 


\section{Abstract}

A process to coat nanoparticle agglomerates has been developed and its critical operation parameters have been studied in this work. It consists on a fluidized bed where a supercritical anti-solvent process (SAS) takes place. Titanium dioxide $\left(\mathrm{TiO}_{2}\right)$, used as model nanoparticle, has been coated with a polymer, Pluronic F-127, from an ethanolic solution. As main factors that can affect the coating process, the following process parameters were studied: the ratio between the velocity of carbon dioxide through the bed and the minimum fluidization velocity $\left(\mathrm{u}_{\mathrm{mf}}\right)$, with values from 1.5 to 2.5 times the umf; the density of carbon dioxide, varying from $640 \mathrm{~kg} / \mathrm{m}^{3}$ to $735 \mathrm{~kg} / \mathrm{m}^{3}$ approximately; the flow rate of solution, within an interval between $0.5-2 \mathrm{~mL} / \mathrm{min}$; the concentration of the solution, from $0.030 \mathrm{mg} / \mathrm{mL}$ to $0.090 \mathrm{mg} / \mathrm{mL}$ and the mass ratio polymer-particle, $0.45-1.8 \mathrm{~g} / \mathrm{g}$. The process parameters were selected taking into account the values that increased the yield, defined as gram of coating material per gram of introduced polymer amount, and maintained a unimodal particle size distribution (PSD), with low increment in the mean particle size with respect to raw $\mathrm{TiO}_{2}$. All the samples were analyzed by four different methods, which showed the successful results of the experiments. The yield was analyzed gravimetrically, and the PSD was determined by laser diffraction. The presence of polymer on the surface of the nanoparticle agglomerates was verified by FT-IR spectrum and fluorescence microscopy, which also showed the quality and uniformity of the coating. Furthermore, the bulk density of the samples was measured showing a lineal variation with the mass ratio polymer-particle. 


\section{Introduction}

Nowadays, nanoparticle technology has found important applications in fields such as electronics, catalysis, biomedicine, biotechnology or food industry. This interest in nanoparticles resides in their small size $(<100 \mathrm{~nm})$, morphology, particle size distribution and composition, which represents a bridge between bulk materials and atomic or molecular structures. However, working with fine particles, agglomeration presents a serious problem because of their strong cohesive forces. Nanoparticles are in 'Geldart group C' [1], which is characterized by the rise of cohesive forces like Van der Waals, electrostatics and liquid bridge forces [2]. Van der Waals force intensity, which is inversely proportional to the diameter to the sixth power, is assumed as the most important cohesive force in nanoparticles that lead to the formation of agglomerates.

A large number of nanoparticles require special treatments in order to improve their properties to be used in some fields such as pharmaceutical, alimentary or fertilizing industries. With the addition of a coating layer, some of their properties can be modified, like hygroscopicity, morphology or bulk density [3]. In addition, this coating is used to protect high value added products, encapsulate hydrophobic and/or toxic substances.

Fluidized bed has been commonly used in many chemical processes in order to encapsulate particles, but nanoparticles cannot be fluidized, only their agglomerates [4]. Several authors have define two different kinds of nanoparticle fluidization, agglomerate particle fluidization (APF) which is characterized by homogeneous bed expansion, absence of bubbles, uniform agglomerates distribution and high expansion relation. This type of fluidization appears in particles with a bulk density lower than 100 
$\mathrm{kg} / \mathrm{m}^{3}$ that form porous light agglomerates. The second type is the agglomerate bubbling fluidization (ABF) which takes place when bulk density is higher than $100 \mathrm{~kg} / \mathrm{m}^{3}$, and it is characterized by low expansion relation and sedimentation of agglomerates, which are weighty and compact $[4,5]$. These characteristics make APF particles profitable for coating since $\mathrm{ABF}$, due to low bed expansion, have a major aggregation tendency [6].

Some technics have been developed to improve cohesive particle fluidization reducing the agglomerates size: ultrasounds, mechanical vibration, mechanical stirring, electrical fields, pulse gas flow, centrifugal field, and secondary flows $[4,7,8]$. In this work supercritical fluids (SCF), whose density and viscosity are easily tunable with small changes in pressure and temperature, are tested; since it has been proved that these properties change the dynamic equilibrium inside the bed enhancing fluidization quality $[6]$.

Furthermore, in the last decades, the use of SCF has grown noticeably in precipitation processes versus conventional techniques [9]. The reason is that the final particle size obtained in the processes, the size distribution and the morphology of the particles can be easily controlled [10]. Depending on the role that SCF performs, there are three different process groups: solvent, anti-solvent or co-solvent. Many authors have used the combination of fluidized beds and supercritical fluids for coating of microparticles, especially RESS process where the SCF acts as solvent. The rapid expansion of the supercritical solution (RESS) causes very high supersaturating ratio of solute in the spraying flow, forming a large number of superfine nuclei. T.J. Wang et al (2001) [3] covered core particles simulating drug compounds with paraffin and obtained a uniform covering with a thickness near $10 \mathrm{~nm}$. In 2002, R.Schreiber et al [11], covered microparticles with a wax. The results were good for most of the experiments with thickness varying from $0.6-0.42 \mu \mathrm{m}$, except for those particles with bigger cores (100- 
$200 \mu \mathrm{m})$ where thin but incomplete covers were obtained. This effect can be explained because of the insufficient mixing inside the fluidized bed. C. Vogt et al (2004) [12] achieved smooth and complete covers over different types of solids, but only with yields near 50\%. In 2008, S. Rodríguez-Rojo et al [13], tested two different ways of injecting a paraffin coating solution in the SC-CO2, bottom and top spray. The results showed the microparticles glass beads were totally covered and no aggregation was achieved when the solution is feed through the top spray. The RESS process limit the range of coating agents that can be used since it must be soluble in the SCF. A better option is performing a process in which the SCF acts like an anti-solvent, like supercritical anti-solvent process (SAS), that has been widely used in preparing micro/nanoparticles because of lower residual solvent in products, simple step and mild operating conditions [14]. To carry on this process the solute of interest has to be dissolved in an organic solvent. The solute must be insoluble in the supercritical phase; however, the organic solvent must be soluble in the SCF. When the solution enters in the super critical phase through a nozzle, the solvent is dissolved in the SCF, which acts as anti-solvent, reaching the super-saturation and causing the precipitation of the solute as fine particles. The only example so far exists consist on a curcumin nanoparticles coated by PLGA using a novel fluidization assisted supercritical anti-solvent procedure [15]. Furthermore, in this work, supercritical anti-solvent is assisted with ultrasonic vibration to improve mixing effects. At best operating conditions the minimum diameter obtain after the coating process is three times the initial diameter but precipitation yields were only of $51 \%$.

This work presents a combination between a supercritical fluidized bed of nanoparticle agglomerates in SCF-CO2, with a SAS process. The objective is to study the coating process of nanoparticle agglomerates with a polymer taking the advantages of the heat 
and mass transference in fluidized bed and the solvent power of SCFs. In addition, the parameters that define the process are discussed in order to optimize the process. Titanium dioxide $\left(\mathrm{TiO}_{2}\right)$ was chosen as nanoparticle model material, meanwhile the selected organic solvent was ethanol (EtOH) due to its high solubility in SCF- $\mathrm{CO}_{2}$ and it is one of the most used in anti-solvent processes $[16,17]$. The coating agent used in all the experiments was Pluronic-127 (F-127), a hydrophylic block copolymer with applications in drug delivery systems [18-20]. Besides, it good properties as coating agent, it has excellent wetting properties in solution and readily forms films after solvent evaporation.

\section{Experimental}

\subsection{Materials}

Titanium dioxide, AEROXIDE® $\mathrm{TiO}_{2} \mathrm{P} 25$, was a gift from Evonik Industries. The powder properties are displayed in Table 1 . As it can be observed in Figure $1, \mathrm{TiO}_{2}$ agglomerates have a porous structure due to cohesive forces. The fluidization agent chosen was carbon dioxide provided by Carburos Metalicos S. A with a purity of 99.95\%. Ethanol, supplied by Panreac with a purity of $99.5 \%$, was selected as organic solvent. The coating agent, Pluronic F-127, with an approximate density of $500 \mathrm{~kg} / \mathrm{m}^{3}$, was supplied by Panreac. Fluorescein sodium salt, purchased from Sigma, has been used as fluorophore to dye the polymer solution.

\subsection{Experimental device}

In Figure 2, a schematic flow diagram of the equipment is displayed. Carbon dioxide, stored in a gas cylinder, T-3, at a pressure around 5.0 - 5.5 MPa, is pumped in liquid state by the membrane pump, P-1 (EH-M-510V1, Lewa) into the first vessel, T-1, until the operating pressure is achieved. The vessel $\mathrm{T}-2$ has been previously charged with $4 \mathrm{~g}$ 
of titanium dioxide, with a volume of $44.5 \mathrm{~cm}^{3}$ according to its bulk density. The operating pressure is controlled at the end of the line by the backpressure valve, $\mathrm{V}-1$ (BP-66, Go Inc.). The vessel T-1 acts like an equalizing reservoir in order to avoid pressure and flow oscillations due to the pulsating flow of the pump. As a good operation of the plant requires high flow of $\mathrm{CO}_{2}$, a recirculation line and a bypass line were implemented in order to reduce the $\mathrm{CO}_{2}$ consumption. Both are simultaneously used and manually controlled by backpressure valve V-2 (BP 301, Pressure Tech) and the valve V-3, respectively. A Coriolis flow controller, FC-1, (Mini Cori-Flow M14RGD-220S, Bronkhorst) is used to maintain a constant flow. After passing through T-1, carbon dioxide goes directly to the second vessel, T-2, which is used for the fluidization. Both vessels have a volume of $1.2 \mathrm{~L}$ and they are heated by a hot-water jacket from two external thermostatic baths in order to reach the operating temperature. Inside $\mathrm{T}-2$, there is a stainless steel basket $(\mathrm{h}=323 \mathrm{~mm} ; \mathrm{d}=41 \mathrm{~mm})$, with stainless steel sintered plates at bottom and top, which is used to introduce the nanoparticles inside the vessel and to make their handling easier. The bottom plate acts as fluid distributor. At the outlet of the fluidized bed vessel, T-2, there is a filter, F-1, to avoid that any dragged particle could be recirculated with the fluid.

Once the operational conditions of pressure and temperature are reached, the solution of the polymer in ethanol is pumped at $318 \mathrm{~K}, \mathrm{P}-2$ (membrane pump EH-M-510V1, Lewa), inside the fluidized bed through a nozzle with an internal diameter of $0.572 \mathrm{~mm}$ situated inside the basket. When the solution get in contact with the supercritical carbon dioxide, the SAS process takes place. The ethanol is solved by the $\mathrm{CO}_{2}$ and this mixture is expanded until ambient conditions in the last vessel, T-3, which acts as a liquid-vapor separator in order to get a gaseous phase rich in $\mathrm{CO}_{2}$ and a liquid phase, ethanol, 
gathered by opening valve V-5. After a defined operating time, there is a drying period of 30 minutes in order to eliminate any residual ethanol from T-2.

\subsection{Product characterization}

In order to determine the coating quality and the process efficiency, several qualitative and quantitative techniques have been used.

\subsubsection{Coating yield}

Coating yield $(\% \eta)$ is defined as the percentage of the ratio of the mass of Pluronic F127 deposited on the particles (mdeposited) to the total amount of polymer pumped into the vessel (mintroduced) ( 1 ). It has been calculated by means of a gravimetric analysis. The samples were divided in three crucible and introduced in a furnace at a temperature of $550{ }^{\circ} \mathrm{C}$ for the period of 72 hours to determine the mass of polymer deposited during the process by weight difference of particles before and after the calcination of the polymer.

$\%$ \% $=\frac{\mathrm{m}_{\text {depesited }}}{\mathrm{m}_{\text {1ntroduesd }}} \times 100$

\subsubsection{Mean particle size and particle size distribution}

In order to determine the particle size distribution, the laser light scattering equipment Malvern Mastersize 2000 in dry via (Scirocco 2000 accessory) with red light (Max. $4 \mathrm{~mW}$ helium-neon, 632.8nm) was used. The equipment has an accuracy and a reproducibility better than $1 \%$. The particle size distribution has been expressed in $\%$ number and $\%$ mass (volume). Besides, the mean particle size of the distribution was characterized by the $\mathrm{d}_{3.2}$, or Sauter Diameter, which is the diameter of a sphere that has the same volume/surface area ratio as the entire particle size distribution. Pluronic F127 refractive index chosen was 1.467 while titanium dioxide was 2.741 . 


\subsubsection{Morphology: Fluorescence Microscopy}

Additionally, in some experiments fluorescein sodium salt was added to F-127 at a concentration of ca. $0.01 \mu \mathrm{g} / \mathrm{mL}$. In this case the fluorescein sodium salt acts like a fluorophore, a chemical compounds that can re-emit light upon light excitation. The samples are illuminated with a green light of a specific wavelength (495 - $570 \mathrm{~nm}$ ) which is absorbed by the fluorophores causing them to emit light of longer wavelengths. By this re-emission, it is possible to observe if the polymer with the fluorescein sodium salt is deposited over the particle surface. The microscopy used to obtain the images of the samples was a Leica DM4000 B (Wetzlar, Germany).

\subsubsection{Bulk density determination}

The bulk density of coated particles was determined as follows, a constant volume of 1 $\mathrm{mL}$ of each sample was measured and then weight in order to calculate the density of the powder. This procedure was repeated five time for each sample to minimize the error.

\subsubsection{Structural characterization: FTIR analysis}

The fingerprint of the pure components and the samples has been determined by Fourier Transform Infrared Spectroscopy (FT-IR) to check the presence of the coating agent on the particle surface and if it covers the core particles completely. IR spectra of the samples were recorded on a Bruker ALPHA FT-IR apparatus equipped with a Platinum ATR module including a diamond crystal. The spectra in the range from $4000 \mathrm{~cm}^{-1}$ to $400 \mathrm{~cm}^{-1}$, were the average of 60 scans at a resolution of $4 \mathrm{~cm}^{-1}$. The ATR signal was transformed to transmittance and the obtained spectra were normalized after the correction of the baseline. 


\section{3 .Results and discussion}

The effect of several operational parameters on yield, final particle size and particle size distribution has been studied. The value of each parameter was chosen to reach the maximum yield and to obtain the narrowest PSD and the smallest mean particle size. These parameters were the flow ratio between the flow rate of carbon dioxide and the minimum fluidization flow rate, the density of the carbon dioxide, the flow of solution, the concentration of the solution and mass ratio polymer-particle. The conditions and the results of all the experiments are gathered in Table 2.

\subsection{Carbon dioxide flow rate}

The effect of the $\mathrm{CO}_{2}$ flow rate has been analyzed in experiments $1-3$, where the ratio u/umf was varied between 1.5 and 2.5 times the $u_{\mathrm{mf}}$. To ensure the fluidization state, the minimum flow selected was 1.5 times the $u_{m f}$. The maximum flow was 2.5 times the $\mathrm{u}_{\mathrm{mf}}$ in order to avoid dragging of the particles. Minimum fluidization velocity ( $\mathrm{umf}_{\mathrm{m}}$ ) for titanium dioxide nanoaglomerates was determined in a previous study $(\mathrm{P}=10.5 \mathrm{MPa}, \mathrm{T}$ $=309.15 \mathrm{~K}, \mathrm{umf}_{\mathrm{mf}}=0.027 \mathrm{~cm} / \mathrm{s}$ ) by the determination of pressure drop across the bed [21] using the system described in Rodriguez-Rojo et al. [22]. As shown in Table 2, the higher the relation $\mathrm{u} / \mathrm{u}_{\mathrm{mf}}$ is, the higher the yield achieved. Besides, the smallest particles were obtained in run 3 , which corresponds to a relation $\mathrm{u} / \mathrm{u}_{\mathrm{mf}}$ of 2.5 as Figure 3 shows. When the flow of carbon dioxide is higher, the fluidized bed is more expanded, the mixing is better [22] and the solution can wet better the particles. In addition, at higher flows, ethanol is faster solubilized and any possible residue on the polymer film can be easily dried resulting in smaller and less agglomerated product.

\subsection{Carbon dioxide density}


Fluid density is an important parameter regarding fluidization, since high values enhance fluidization, as fluid molecules are closer. Supercritical carbon dioxide density can be easily tuned by moderate changes in pressure and temperature. Besides, its solvent power is also modified [22].

In this work the variation of pressure and temperature was limited due to the reduction of the melting point of the polymer in the presence of pressurized $\mathrm{CO}_{2}$ to $310.1 \mathrm{~K}$ at pressure above $8.8 \mathrm{MPa}$. Therefore, operating temperature was fixed at $309 \mathrm{~K}( \pm 1)$ and the minimum operating pressure was set at $8.8 \mathrm{MPa}$ [23]. So, the operating temperature was always below this value. Runs 3,4 and 5 are compared, with densities near 700 $\mathrm{kg} / \mathrm{m}^{3}, 642 \mathrm{~kg} / \mathrm{m}^{3}$ and $733 \mathrm{~kg} / \mathrm{m}^{3}$ respectively. On one hand, the yield increases with the density because the solvent power of the carbon dioxide increases and ethanol is better solubilized. On the other hand, there is not a clear tendency in the product size variations with the density. Density is a difficult variable to control since it depends on pressure and temperature and it can affect the growing kinetics and the deposition effect. Furthermore, the variations in temperature and pressure would affect to the transport properties of the fluid. Nevertheless, the value, which produces the thinner coating (i.e. product particle size distribution most similar to the initial one), is 700 $\mathrm{kg} / \mathrm{m}^{3}$ (P: $\left.10.1 \mathrm{MPa}, \mathrm{T}: 309 \mathrm{~K}\right)$. However, at this value the yield $(95.1 \%)$ is slightly lower than the obtained at higher densities $\left(733 \mathrm{~kg} / \mathrm{m}^{3}\right.$, P: $\left.10.8 \mathrm{MPa}, \mathrm{T}: 308 \mathrm{~K}, 99.5 \%\right)$.

\subsection{Solution flow rate}

The volumetric flow rate of the solution was also tested with three different values, 0.5 $\mathrm{mL} / \mathrm{min}, 1 \mathrm{~mL} / \mathrm{min}$ and $2 \mathrm{~mL} / \mathrm{min}$, in runs 12,11 and 6 , respectively. These values were selected taking into account SAS process studies of other authors [24-26], where the mass flow of $\mathrm{CO}_{2}$ varies from $0.5-2 \mathrm{~kg} / \mathrm{h}$. The results showed in Table prove that the yield decreases with solution flow because when more, and also faster, ethanol is 
introduced in the fluidized bed, more difficult will be to remove it. Theoretically, $\mathrm{CO}_{2}$ and ethanol find itself, according to the phase diagram, in a unique phase at experimental conditions. However, in the presence of F-127 this equilibrium varies and it might be possible not to be a unique phase which complicate the drying. In the case of the final diameter of the particles, no significate changes can be seen. All $\mathrm{d}_{3,2}$ values are between 3-5.5 $\mu \mathrm{m}$. This behavior could be caused by the fact that the deposited amount of polymer does not increase with the solution flow because the polymer-particle mass ratio is kept constant [25]. A different behavior for the yield is observed in the work of F. Zabihi et al.[15], where the yield increases with the solution flow. Besides, the highest yield value achieved is smaller (50\%) than the presented in this work $(92 \%)$. Another difference between both works resides in the tendency of the final particle size. F. Zabihi et al. obtained diameters varying from 700-63 nm, meanwhile the diameters achieved in this work are between 3-5.5 $\mu \mathrm{m}$

\subsection{Solution concentration}

Three different concentrations of the solution were tested: $0.03 \mathrm{~g} / \mathrm{mL}, 0.06 \mathrm{~g} / \mathrm{mL}$ and $0.09 \mathrm{~g} / \mathrm{mL}$, being the last concentration the solubility value that has been found experimentally for F-127 in ethanol at $318 \mathrm{~K}$. The operating time for each concentration was: $60 \mathrm{~min}, 30 \mathrm{~min}$ and $20 \mathrm{~min}$, respectively for runs $6,7,8$, in order to obtain the same polymer-particle ratio. Overall, the results presented in Table 2 show that the yield decrease with the concentration. The main reason for this behavior is that, the more concentrate the solution is, the faster the process is, and hence, there is not enough time to distribute the polymer uniformly over the agglomerate surface.

Furthermore, the diameter of the coated particles did not show significant differences between the three experiments, with values for $d_{3,2}$ between $0.8-1.0 \mu \mathrm{m}$, being the 
smallest for a concentration of $0.03 \mathrm{~g} / \mathrm{mL}$. Similarly, particle size distribution in number did not show important differences between the three experiments, apart from the fact that PSD at $0.03 \mathrm{mg} / \mathrm{mL}$ show a multimodal distribution in the same range of particle size (Figure 4). Therefore, the PSD in volume was analyzed since it allows detecting the presence of big agglomerates. These data are collected in Figure 5 and show that the biggest particles are obtained with a concentration of $0.03 \mathrm{mg} / \mathrm{mL}$, which, in principle, is not coherent since the deposition velocity is smaller. This result can be explained taking into account that the experiment time is longer in this case (60 $\mathrm{min})$ to achieve the same theoretical polymer-particle ratio. Therefore, more ethanol was used that may have make more difficult the drying process producing a bigger number of agglomerates. Meanwhile, the smallest particles are obtained with a concentration of $0.06 \mathrm{mg} / \mathrm{mL}$.

\subsection{Mass ratio polymer-particle}

Four different values of $\mathrm{m}_{\text {polymer }} / \mathrm{m}_{\text {particle }}(\mathrm{g} / \mathrm{g})$ were tested: $0.45,0.9,1.35$ and $1.8 \mathrm{~g} / \mathrm{g}$ in runs $6,3,9$ and 10 respectively. These values have been selected according to the literature [27]. The variation of the yield with the mass ratio showed a convex form with a maximum value near $0.9 \mathrm{~g} / \mathrm{g}$. Besides, with this mass ratio the obtained particle size distribution is closer to the initial size distribution of $\mathrm{TiO}_{2}$. This behavior is explained for the same reason as in the previous section: on one hand, if the ratio $\mathrm{m}_{\text {polymer }} / \mathrm{m}_{\text {particle }}(\mathrm{g} / \mathrm{g})$ increases, the number of agglomerates also increase and there is no uniformity on the product size.

Due to the fact that the yield is calculated by the weight difference between the calcined and the total amount of polymer introduced there must be a minimum quantity of polymer, as Wang et al. indicated [28], to encapsulate the particle. This parameter cannot be optimize because it depends on the requirement of the product. Also, the 
thickness of the coating depends on a technical limitation as the tendency on Figure 6 shows. This behavior is also explained by other authors [29]. There is a maximum quantity of polymer that can be deposited because the deposition is formed by a layer succession. The theoretical coating thickness varies from 5 to $25 \mathrm{~nm}$, depending on the time and, at long time the thickness approaches a constant value. Thickness was calculated assuming that the particles are spheres and the polymer is distributed uniformly (vide equation ( 2 ))).

$V_{T}=\frac{4}{3} \cdot \pi \cdot\left(r_{p}+t\right)^{3}=V_{P}+V_{D}$

Where $\boldsymbol{r}_{\boldsymbol{p}}$ is the averaged radius of the particle, $\boldsymbol{t}$ the thickness of the coating, $\boldsymbol{V}_{\boldsymbol{T}}$ is the total volume of the particle with the polymer, $\boldsymbol{V}_{\boldsymbol{p}}$ the volume of the particle without the polymer and $\boldsymbol{V}_{\boldsymbol{D}}$ the volume of the deposited polymer. The latter is calculated by the relation between the mass of the particle and the amount of polymer (equation 3). Where $\rho$ polymer is the density of the polymer, $\mathbf{R}$ the mass ratio between polymer and particle and $\boldsymbol{\eta}$ coating yield.

$\mathrm{V}_{\mathrm{D}}=\left(\mathrm{R} \cdot \mathrm{m}_{\text {particle }}\right) / \rho_{\text {polymer }} \cdot \eta$

(3)

However, it is possible to define an optimum operational range taking into account values of yield and particle size, from value $1 \mathrm{~g} / \mathrm{g}$ and $1.4 \mathrm{~g} / \mathrm{g}$. Working at mass ratio near $2 \mathrm{~g} / \mathrm{g}$, the number of agglomerates and the product size increase dramatically. If more time is required, more ethanol will be introduced and the drying will be more difficult. 


\subsection{Bulk density}

An interesting property modified with the coating is bulk density. When particles are coated, their bulk density changes as more matter is added to the substance. Titanium dioxide presents a very low bulk density, $90 \mathrm{~kg} / \mathrm{m}^{3}$, which makes difficult to handle it. The coating process increases linearly the bulk density of the powder with the mass ratio polymer-particle, as shown in Figure 7 and improves their handling. This evidence the presence of a polymer coating and it is an easy way to analyze if the process is working properly.

\subsection{Morphology: Fluorescence Microscopy}

Fluorescence microscopy was used in order to prove the polymer was deposited over the surface of the nanoparticles agglomerates. As shown in Figure 8, the polymer dyed with fluorescein sodium salt is uniformly distributed over the agglomerates. Therefore, it is showed that this new method is suitable for a good coating of nanoparticle agglomerates.

\subsection{FT-IR spectrums}

The deposition of Pluronic over titanium dioxide particles surface has been demonstrated also by FT-IR analysis. To perform these analysis, a representative and homogeneus quantity of the coated particles from each experiment were used. Coated particles from all experiments have a similar fingerprint. These spectrums, as shown in Figure 9, are similar to that of titanium dioxide and present the most representative Pluronic peaks at 1,100 and $2,900 \mathrm{~cm}^{-1}$. Since the penetration beam of the equipment is $2 \mu \mathrm{m}$, the thickness of the coating agent is totally pierced being the major sample 
compound analyzed titanium dioxide in all the cases. Nevertheless, these spectrums are a hint that particles are covered with the polymer.

\section{Conclusions}

A nanoparticle agglomerate coating technique in a fluidized bed via SAS process has been studied and its operational parameters have been analyzed. This process, combining the advantageous characteristics of fluidized beds (good mass and heat transfer and easy temperature control) and anti-solvent process, has been found to be a good alternative to cover nanoparticle agglomerates obtaining thin and uniform coatings maintaining a narrow and unimodal distributions. Further, the operational parameters were selected based on the yield and the PSD.

Although a statistical studio was not done, the variables that have produce more variations on the yield are the solution flow and the solution concentration. In the range studied, this parameter change from $30 \%$ to $100 \%$, being the best option to work at low flows and dilute concentrations. Meanwhile, the mass ratio polymer-particle affects significantly the final particle size varying from $0.60-3.00 \mu \mathrm{m}$. In addition, it is not a parameter that can be optimize because it depends on the specifications of the product and also on the operational maximum due to the formation of the coating by a layer succession.

Furthermore, it was observed by fluorescence microscopy that the polymer was present over the whole agglomerate surface. Other evidence that shows this process works is the variation on the bulk density, which increases linearly with the ratio polymerparticle. Besides, the FT-IR spectrum point out there are variations between the result for the particle with polymer and without it. Thanks to the coating, the bulk density changed and the manipulation of the particles is enhanced. 


\section{Acknowledgements}

This work is partially supported by the project Shyman FP7-NMP-2011-LARGE280983 and the project CTQ2013-44143-R of the Spanish Ministerio de Economía y Competitividad. Víctor Martín thanks the University of Valladolid for his doctoral grant. Rut Romero-Díez would like to thanks her agreement with the University of Valladolid. Soraya Rodríguez-Rojo thanks the Spanish Ministerio de Ciencia e Innovación and the University of Valladolid for her Juan de la Cierva fellowship (JCI2012-14992). 


\section{NOMENCLATURE}

ACRONYMS

SAS: Supercritical Anti-solvent Process.

RESS: Rapid Expansion of Supercritical Solutions.

GAS: Gas Anti-solvent

PCA: Precipitation with a compressed fluid Anti-solvent)

PGSS: Precipitation from a Gas Saturated Solution

SCF: Supercritical Fluid.

PSD: Particle Size Distribution.

FT-IR: Fourier Transform Infrared Spectroscopy.

APF: Agglomerate Particle Fluidization.

ABF: Agglomerate Bubbling Fluidization.

EtOH: Ethanol

$S Y M B O L S$

$u_{m f}$ : Minimum fluidization velocity, $\mathrm{cm} / \mathrm{s}$

$P$ : Operating pressure, $\mathrm{MPa}$

$T$ : Operating temperature, $\mathrm{K}$.

C : Operating solution concentration, $\mathrm{mg} / \mathrm{mL}$. 


\author{
$\underline{m_{\text {polvmer }}}$ \\ $m_{\text {particle }}$ : Mass ratio between the polymer and the particle, $\mathrm{g} / \mathrm{g}$.

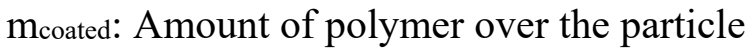 \\ mintroduced: Amount of polymer pumped in fluidization chamber \\ $V_{T}:$ Total volume of the coated particle, $\mathrm{m}^{3}$. \\ $r_{p}:$ Radius of the particle, $\mathrm{m}$. \\ $t$ : Thickness of the deposited layer of polymer, $\mathrm{m}$. \\ $V_{D}:$ Deposited volume of the polymer, $\mathrm{m}^{3}$. \\ $\rho_{P}:$ Density of the particle, $\mathrm{kg} / \mathrm{m}^{3}$. \\ $\eta$ : Coating yield
}

\title{
REFERENCES
}

1. D. Geraldt, Types of gas fluidization. Powder Technology, 1973. 7(5): p. 285-292.

2. J. Visser, Van Der Waals and Other Cohesive forces affecting Powder Fluidization. Powder Technology, 1989. 58: p. 1 - 10.

3. A. Tsutsumi T. J. Wang, H. Hasegawa, T. Mineo, Mechanism of particle coating granulation with RESS process in a fluidized bed. Powder Technology, 2001. 118: p. 229-235.

4. J. Ruud van Ommen, J. M. Valverde, and R. Pfeffer, Fluidization of nanopowders: a review. J Nanopart Res 2012. 14: p. 737.

5. W. Yao, G. Guangsheng, W. Fei, W. Jun, Fluidization and agglomerate structure of SiO2 nanoparticles. Powder Technology 2002. 124: p. 152-159.

6. C. Vogt, R. Schreiber, G. Brunner, J. Werther, Fluid dynamics of the supercritical fluidized bed. Powder Technology, 2005. 158(1-3): p. 102-114.

7. E. K. Levy and B. Celeste, Combined effects of mechanical and acoustic vibrations on fluidization of cohesive powders. Powder Technology, 2006. 163: p. 41-50.

8. J. M. Valverde, M. J. Espin, M. A. S. Quintanilla,. A. Castellanos, Electrofluidized bed of silica nanoparticles. Journal of Electrostatics 2009. 67: p. 439-444.

9. R. Schreiber, B. Reinke, C. Vogt, J. Werther, G. Brunner, High-pressure fluidized bed coating utilizing supercritical carbon dioxide. Powder Technology, 2003. 138: p. 31-38. 
10. I. Kikic, N. Zordi, M. R. Moneghini, .D. Solinas, Solubility estimation of drugs in ternary systems of interest for the antisolvent precipitation processes. The Journal of Supercritical Fluids, 2010. 55(2): p. 616-622.

11. R. Schreiber, C. Vogt, J. Werther, G. Brunner, Fluidized bed coating at supercritical fluid conditions. Journal of Supercritical Fluids, 2002. 24: p. 137-151.

12. C. Vogt, R. Schreiber, J. Werther, G. Brunner, Coating of particles in a fluidized bed operated at supercritical fluid conditions. Chem. Eng. Technol., 2004. 27: p. 943-945.

13. S. Rodríguez-Rojo, J. Marienfeld, and M. J. Cocero, RESS process in coating applications in a high pressure fluidized bed enviroment: Bottom and top spray experiments. Chemical Engineering Journal, 2008. 144: p. 531-539.

14. A. Martín, S. Varona, A. Navarrete, M. J. Cocero, Encapsulation and co-precipitation precesses with supercritical fluids: applications with essential oils. Open Chemical Engineering, 2010. 4: p. 31-41.

15. F. Zabihi, S. L. N. Xin, J. Jia, T. Cheng, Y. Zhao, Polymeric coating of fluidizing nanocurcumin via anti-solvent supercritical method for sustained release. The Journal of Supercritical Fluids, 2014. 89: p. 99-105.

16. M. Rossmann, A. Braeuer, A. Leipertz, E. Schluecker, Manipulating the size, the morphology and the polymorphism of acetaminophen using supercritical antisolvent (SAS) precipitation. The Journal of Supercritical Fluids, 2013. 82: p. 230-237.

17. M. Rossmann, A. Braeuer, S. Dowy, T. G. Gallinger, A. Leipertz, E. Schluecker, Solute solubility as criterion for the appearance of amorphous particle precipitation or crystallization in the supercritical antisolvent (SAS) process. The Journal of Supercritical Fluids, 2012. 66: p. 350-358.

18. D. L. Sellers, T. H. Kim, C. W. Mount, S. H. Pun, P. J.Horner, Poly(lactic-co-glycolic) acid microspheres encapsulated in Pluronic F-127 prolong hirudin delivery and improve functional recovery from a demyelination lesion. Biomaterials, 2014. 35(31): p. 8895-8902.

19. J. C. Gilbert, J. Hadgraft, A. Bye, L. G. Brookes, Drug release from Pluronic F-127 gel. International Journal of Pharmaceutics, 1986. 32(2-3): p. 223-228.

20. M. Farrugia, S. P. Morgan, C. Alexander, M. L. Mather, Ultrasonic monitoring of drug loaded Pluronic F127 micellular hydrogel phase behaviour. Materials Science and Engineering:, 2014. 34: p. 280-286.

21. V. Martín, S. Rodriguez-Rojo, M. J. Cocero, Determination of Minimum Fluidization Velocity of Nanoparticle Agglomerates Using High Pressure Carbon Dioxide. 6th International symposium on high pressure processes technology, Belgrade, Serbia, 2013.

22. S. Rodríguez-Rojo, N. López-Valverde, M. J. Cocero, Residence time distribution studies of high pressure fluidized bed of microparticles. The Journal of Supercritical Fluids, 2007. 44: p. 433-440.

23. M. Fraile , Á. Martína, D. Deodatob, S. Rodriguez-Rojoa, I.D. Nogueirad, A.L. Simplíciob, M.J. Cocero, C.M.M. Duarte, Production of new hybrid systems for drug delivery by PGSS (Particles from Gas Saturated Solutions) process. Journal of Supercritical Fluids, 2013. 81: p. 226-235.

24. F. Niu, J. Haslam, R. Rajewski, B. Subramaniam, A fluidized-bed coating technology using near-critical carbon dioxide as fluidizing and drying medium. The Journal of Supercritical Fluids, 2012. 66: p. 315-320.

25. H. Jin, F. Xia, C. Jiang, Y. Zhao, L. He, Nanoencapsulation of Lutein with Hydroxypropylmethyl Cellulose Phthalate by Supercritical Antisolvent. Chiese Journal of Chemical Engineering, 2009. 17(4): p. 672-677.

26. R. N. Dave, Y. Wang, R. Pfeffer, Polymer coating/encapsulation of nanoparticles using a supercritical anti-solvent process. The Journal of Supercritical Fluids, 2004. 28(1): p. 85-99.

27. Y. Wang, Y. Wang, J. Yana, R. Pfeffer, R. Dave, B. Michniak, The application of a supercritical antisolvent process for sustained drug delivery. Powder Technology, 2006. 164(2): p. 94-102. 
28. I. N. Uzun, O. Sipahigil, S. Dinçer, Coprecipitation of Cefuroxime Axetil-PVP composite microparticles by batch supercritical antisolvent process. The Journal of Supercritical Fluids, 2011. 55(3): p. 1059-1069.

29. H. Kröber and U. Teipel, Microencapsulation of particles using supercritical carbon dioxide. Chemical Engineering and Processing, 2005. 44: p. 215-219. 


\section{Figure captions}

Figure 1: SEM photography of titanium dioxide.

Figure 2: Schematic flow diagram of the equipment.

Figure 3: Variation of the final particle diameter and the particle size distribution with the flow of carbon dioxide.

Figure 4: Variation of the final particle diameter and the particle size distribution with the concentration of the solution.

Figure 3: Variation of the final particle diameter and the particle size distribution with the concentration of the solution in \% volume.

Figure 6: Variation of the thickness of the coating with the operating time.

Figure 7: Variation of the bulk density with the mass ratio polymer-particle.Figure 8 : photograph of run No.5 without/with green light illumination.

Figure 9: FT-IR 
Figure (s)

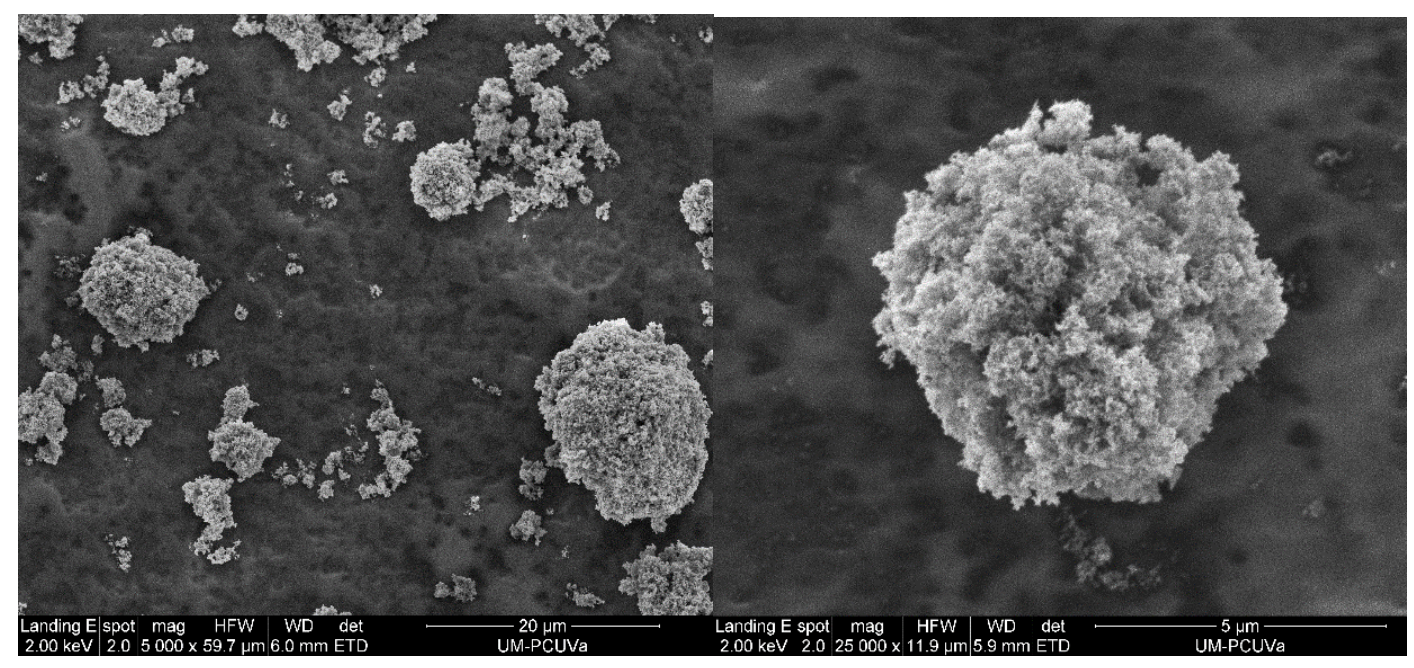

Figure 1: SEM photography of titanium dioxide. 
Figure (s)

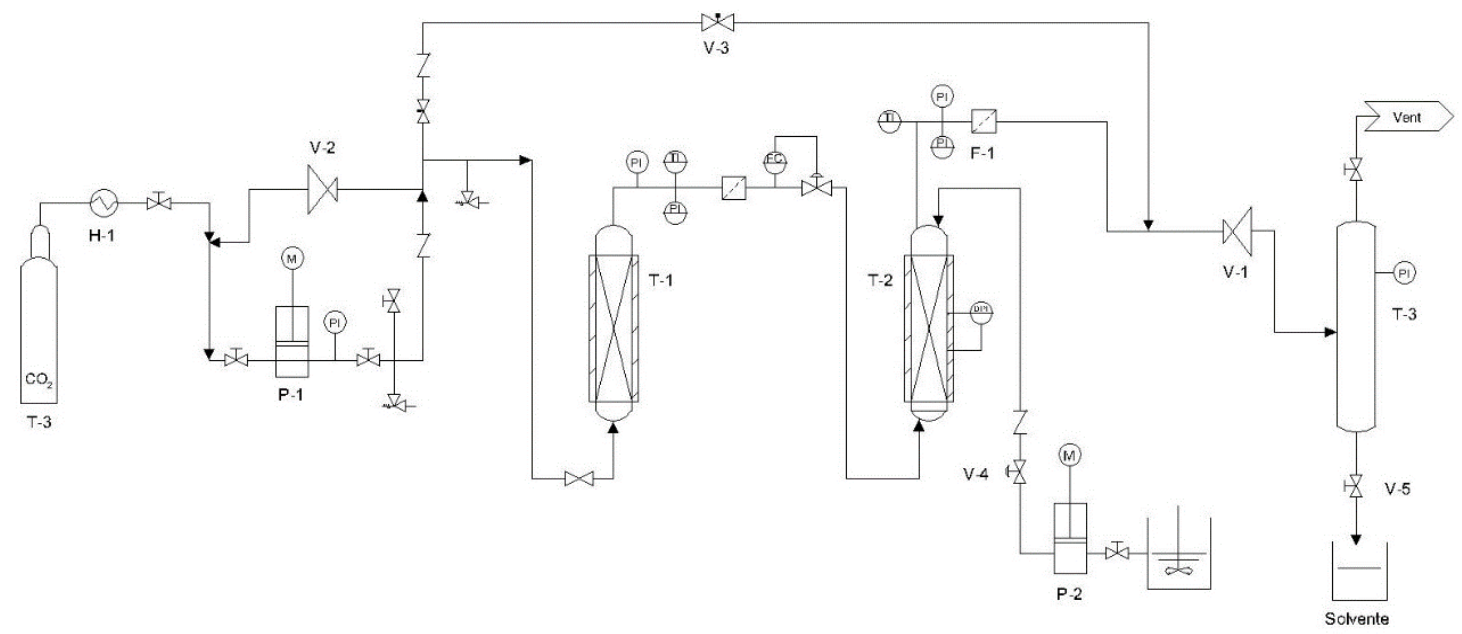

Figure 2: Schematic flow diagram of the equipment. 
Figure (s)

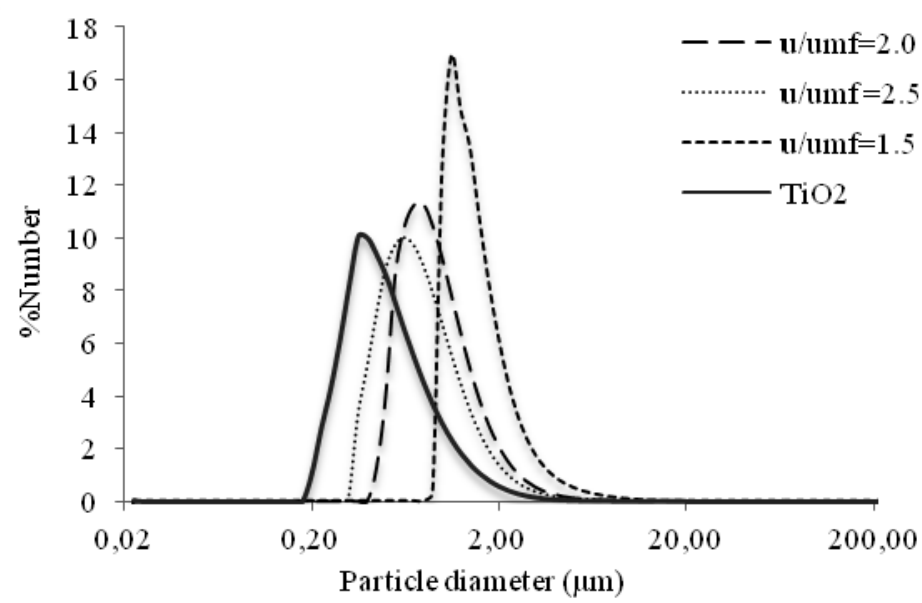

Figure 3: Variation of the final particle diameter and the particle size distribution with the flow of carbon dioxide. 
Figure (s)

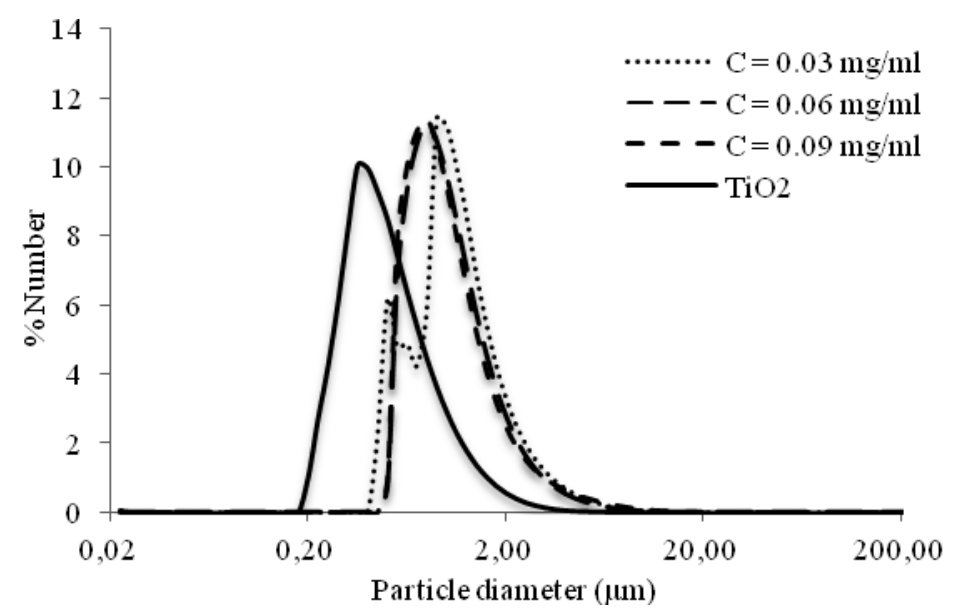

Figure 4: Variation of the final particle diameter and the particle size distribution with the concentration of the solution. 
Figure (s)

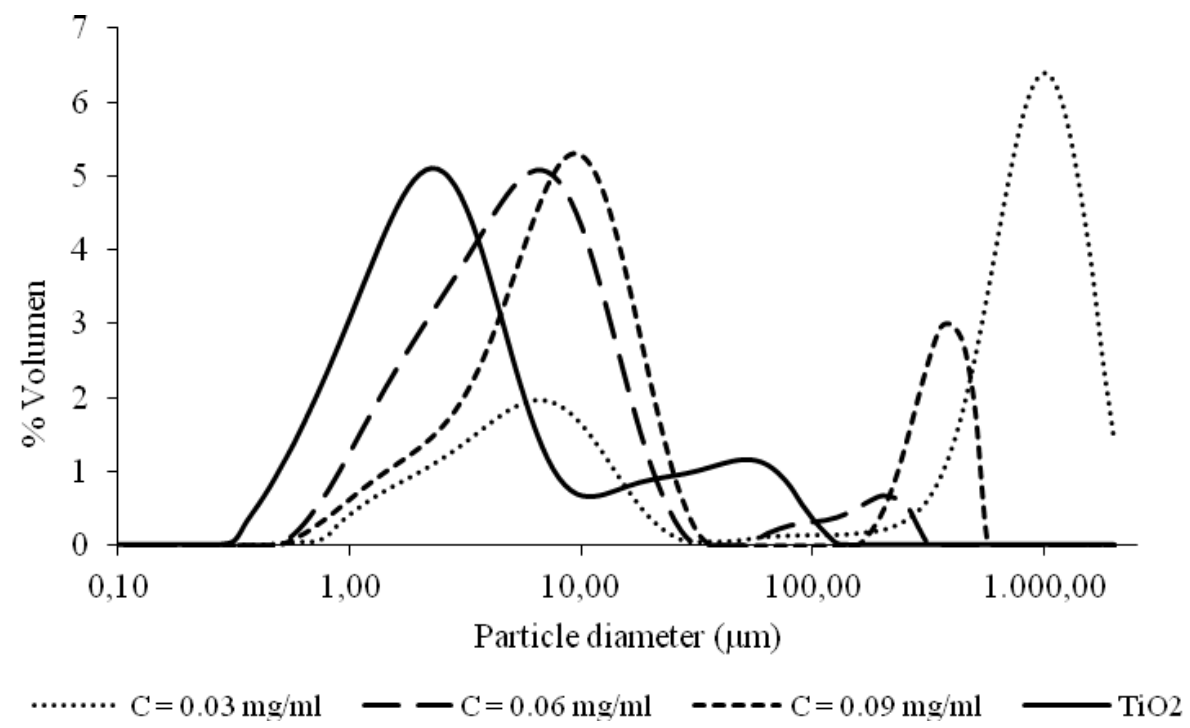

Figure 3: Variation of the final particle diameter and the particle size distribution with the concentration of the solution in \% volume. 
Figure (s)

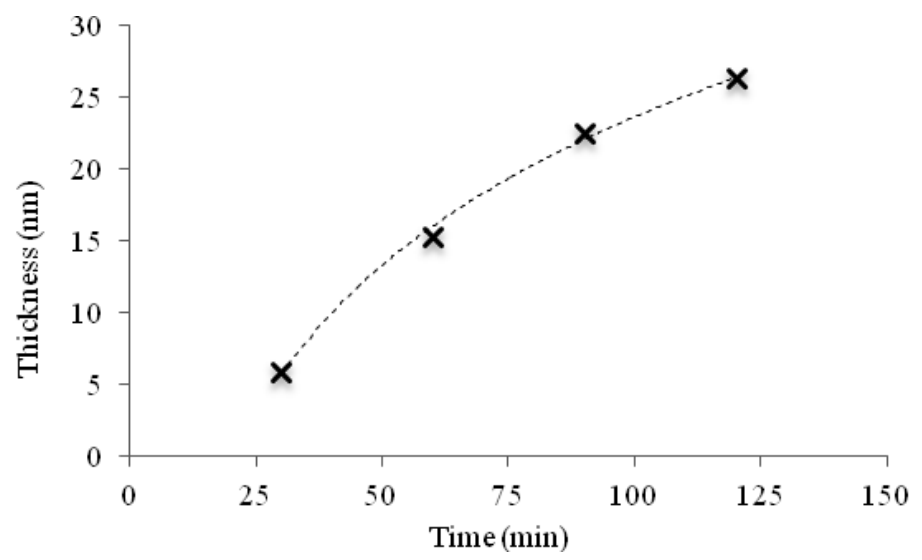

Figure 6: Variation of the thickness of the coating with the operating time. 
Figure (s)

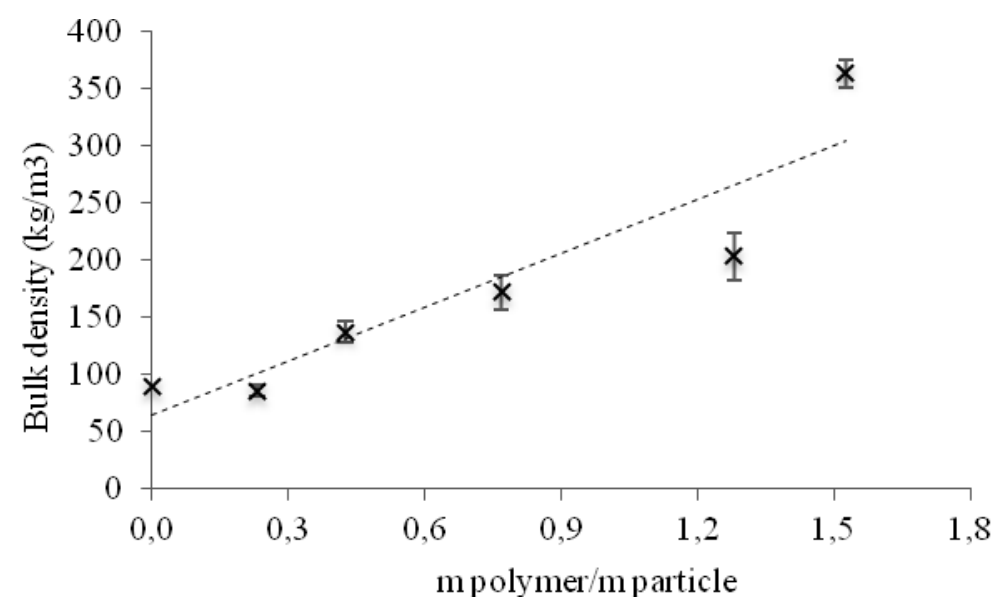

Figure 7: Variation of the bulk density with the mass ratio polymer-particle 
Figure (s)
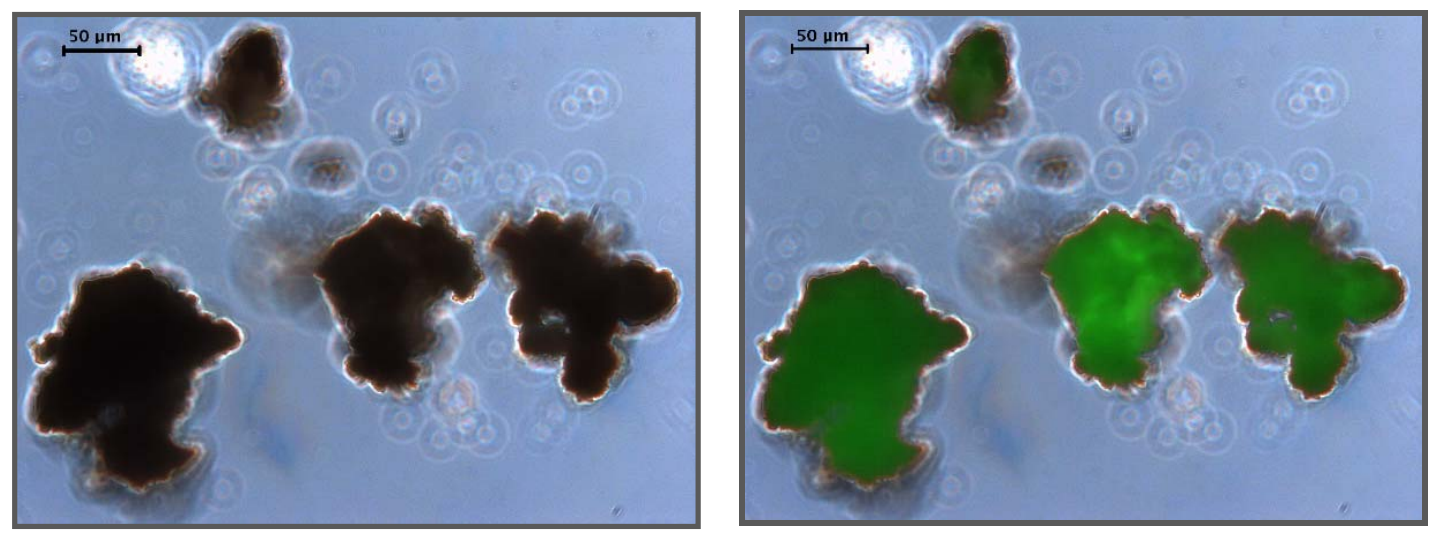

Figure 8: photograph of run No.5 without/with green light illumination. 
Figure (s)

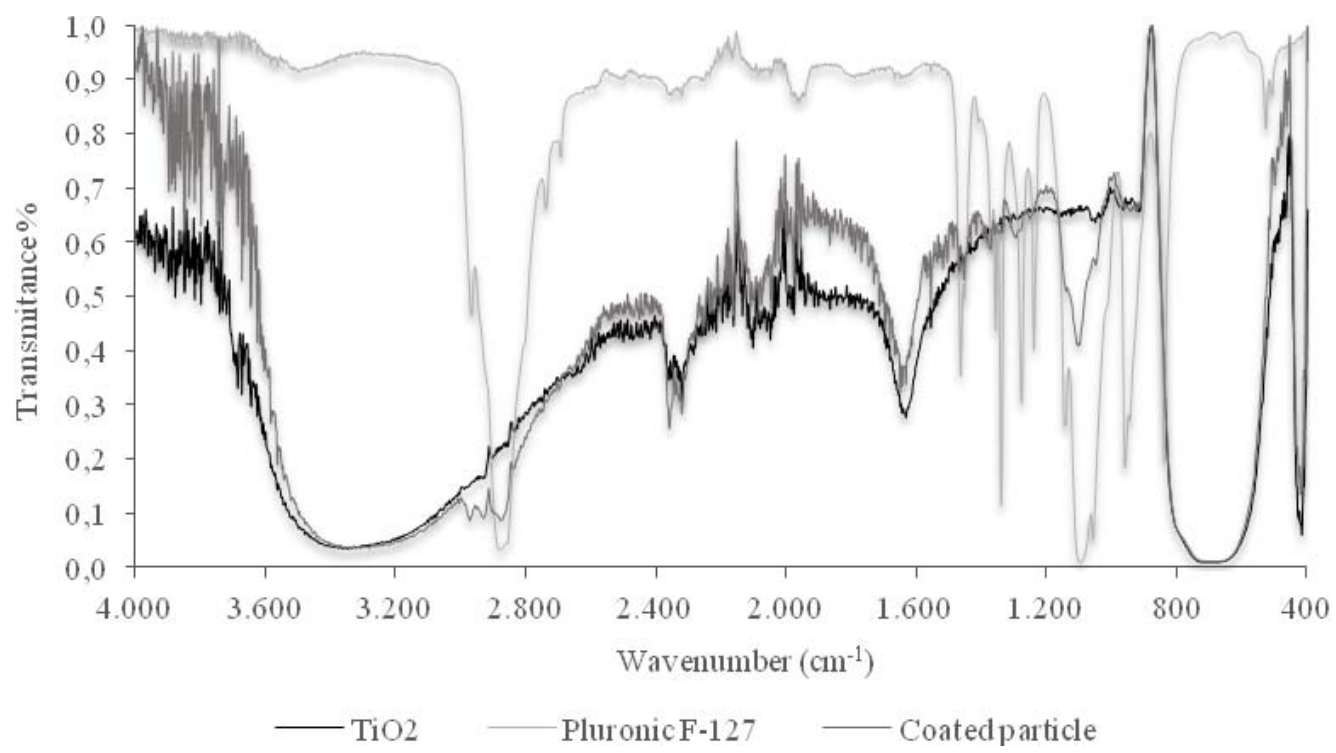

Figure 9: FT-IR spectrum of the experiment at conditions of; $\mathrm{CO}_{2}$ flow: $2.5 \cdot u m f$; solution flow: $0.5 \mathrm{~mL} / \mathrm{min}$; solution concentration: $0.04 \mathrm{mg} / \mathrm{mL}$; $\mathrm{CO}_{2}$ density: $700 \mathrm{~kg} / \mathrm{m}^{3}$; ratio polymer-particle: $0.3 \mathrm{~g} / \mathrm{g}$ 


\section{List Table}

Table 1: Powder physical properties.

Table 2: Conditions and results of F-127-coated titanium dioxide in a fluidized via supercritical antis-solvent process $(S A S)$. Titanium dioxide with average d3,2 $=2.2 \mu \mathrm{m}$ 
Table (s)

Table 1: Powder physical properties.

\begin{tabular}{|c|c|c|c|c|}
\hline Powder & $\begin{array}{c}\text { Size } \\
(\mathrm{nm})\end{array}$ & $\begin{array}{c}\text { Skeletal density } \\
\left(\mathrm{kg} / \mathrm{m}^{3}\right)\end{array}$ & $\begin{array}{c}\text { Bulk density } \\
\left(\mathrm{kg} / \mathrm{m}^{3}\right)\end{array}$ & $\begin{array}{c}\text { Tapped density } \\
\left(\mathrm{kg} / \mathrm{m}^{3}\right)\end{array}$ \\
\hline $\mathrm{TiO}_{2}$ & 21 & 3800 & 90 & 130 \\
\hline
\end{tabular}


Table (s)

Table 2: Conditions and results of F-127-coated titanium dioxide in a fluidized via supercritical antis-solvent process

(SAS). Titanium dioxide with average $d_{3,2}=2.2 \mu \mathrm{m}$

\begin{tabular}{|c|c|c|c|c|c|c|c|c|c|c|c|}
\hline No. & $\begin{array}{c}\mathbf{P} \\
(\mathbf{M P a})\end{array}$ & $\begin{array}{c}\mathbf{T} \\
\mathbf{( K )}\end{array}$ & $\begin{array}{c}\text { Density } \\
\left(\mathbf{k g} / \mathbf{m}^{\mathbf{3}}\right)\end{array}$ & $\begin{array}{c}\mathbf{C O} \mathbf{O}_{\mathbf{f}} \mathbf{f l o w} \\
\mathbf{r a t e} \\
(\mathbf{m L} / \mathbf{m i n})\end{array}$ & $\mathbf{u} / \mathbf{u}_{\mathbf{m f}}$ & $\begin{array}{c}\text { Solution } \\
\mathbf{f l o w} \mathbf{r a t e} \\
(\mathbf{m L} / \mathbf{m i n})\end{array}$ & $\begin{array}{c}\text { Solution } \\
\text { concentration } \\
(\mathbf{g} / \mathbf{m L})\end{array}$ & $\begin{array}{c}\text { Ratio } \\
\text { polymer- } \\
\mathbf{p a r t i c l e} \\
(\mathbf{g} / \mathbf{g})\end{array}$ & $\begin{array}{c}\text { Yield } \\
\mathbf{( \% )}\end{array}$ & $\begin{array}{c}\text { Time } \\
(\mathbf{m i n})\end{array}$ & $\begin{array}{c}\mathbf{d}_{3,2} \\
(\mu \mathrm{m})\end{array}$ \\
\hline $\mathbf{1}$ & 10.5 & 308.1 & 731.0 & 31.9 & 1.5 & 1.0 & 0.06 & 0.90 & 79.9 & 60 & 3.7 \\
\hline $\mathbf{2}$ & 10.2 & 309.7 & 699.0 & 43.9 & 2.0 & 1.0 & 0.06 & 0.90 & 94.1 & 60 & 2.7 \\
\hline $\mathbf{3}$ & 10.1 & 309.4 & 700.5 & 55.7 & 2.5 & 1.0 & 0.06 & 0.90 & 95.1 & 60 & 2.6 \\
\hline $\mathbf{4}$ & 8.8 & 308.4 & 642.3 & 47.3 & 2.5 & 1.0 & 0.06 & 0.90 & 81.2 & 60 & 3.3 \\
\hline $\mathbf{5}$ & 10.8 & 308.7 & 733.2 & 53.2 & 2.5 & 1.0 & 0.06 & 0.90 & 99.5 & 60 & 4.6 \\
\hline $\mathbf{6}$ & 10.4 & 309.5 & 722.0 & 54.0 & 2.5 & 1.0 & 0.06 & 0.45 & 71.4 & 30 & 3.0 \\
\hline $\mathbf{7}$ & 10.2 & 307.6 & 707.0 & 55.2 & 2.5 & 1.0 & 0.03 & 0.45 & 93.2 & 60 & 3.3 \\
\hline $\mathbf{8}$ & 10.5 & 309.0 & 727.7 & 53.6 & 2.5 & 1.0 & 0.09 & 0.45 & 23.5 & 20 & 4.3 \\
\hline $\mathbf{9}$ & 10.0 & 308.4 & 723.0 & 54.0 & 2.5 & 1.0 & 0.06 & 1.80 & 83.8 & 120 & 12.6 \\
\hline $\mathbf{1 0}$ & 10.1 & 307.3 & 728.0 & 53.6 & 2.5 & 1.0 & 0.06 & 1.35 & 94.7 & 90 & 3.6 \\
\hline $\mathbf{1 1}$ & 10.6 & 309.6 & 719.0 & 54.2 & 2.5 & 2.0 & 0.06 & 0.45 & 29.3 & 15 & 5.5 \\
\hline $\mathbf{1 2}$ & 10.3 & 307.2 & 735.0 & 53.1 & 2.5 & 0.5 & 0.06 & 0.45 & 91.7 & 60 & 3.3 \\
\hline
\end{tabular}

